\title{
A noiva e o estribilho: uma análise da música preexistente em um filme de Truffaut ${ }^{1}$
}

\section{Luíza Beatriz A. M. Alvim}

\section{Resumo}

Em A noiva estava de preto (François Truffaut, 1968), a protagonista Julie se vinga dos cinco homens responsáveis pela morte de seu noivo. Duas músicas preexistentes, o Concerto para bandolim, de Vivaldi, e a Marcha Nupcial, de Mendelssohn, acompanhamna como estribilhos. A primeira se relaciona ao modo de enumeração da história, próprio dos contos de fada e marcado pela repetição, presente também na estrutura da música. Já a Marcha Nupcial é ouvida à medida que a cena originária, a saída do casal da igreja, é repetida com diferenças. Consideramos os conceitos de estribilho, repetição (Deleuze) e origem (Benjamim) e fazemos uma análise fílmica das sequências com as duas músicas preexistentes.

\section{Palavras-Chave}

Cinema. Música no cinema. François Truffaut. Análise fílmica.
Luíza Beatriz A. M. Alvim I luizabeatriz@yahoo.com Doutora em Comunicação pela Universidade Federal do Rio de Janeiro - UFRJ, Brasil. Foi professora substituta na Escola de Comunicação da UFRJ e atualmente é pós-doutoranda em Música na UFRJ.

\section{Introdução}

0 filme A noiva estava de preto (1968), de François Truffaut, conta com música de Bernard Herrmann, em uma homenagem e reverência de Truffaut às trilhas musicais dos filmes do mestre Alfred Hitchcock. Como na obra deste último, há uma loira (Jeanne Moreau) e crimes: Julie Kohler é uma mulher que, saindo recém-casada da igreja, vê o noivo-marido tombar por ter sido atingido por uma bala. A noiva, inconsolável para sempre, vai eliminar, anos depois, cada um dos cinco homens que, ao brincarem com um rifle, foram responsáveis pela morte do seu amado.

Para além da música de Herrmann, uma melodia é recorrente nos primeiros momentos em que Julie vai colocando seu plano em ação: 0 Concerto para bandolim em Dó Maior RV425, de Vivaldi. Outra música recorrente no filme é a Marcha Nupcial, de Mendelssohn, presente já nos créditos iniciais e que tem uma relação referencial com o tema do casamento.

0 constante retorno dessas músicas se reporta tanto à forma como o filme é narrado, no modo de 
enumeração, tal qual nos contos de fada, quanto ao fato de que a cena originária de todo o enredo está sempre presente na mente de Julie e é reapresentada mais de uma vez ao espectador: a saída da igreja e 0 tiro que desfaz o sonho de felicidade.

Vamos aqui considerar essas duas músicas preexistentes, levando em conta, primeiramente, os conceitos filosóficos de ritornelo e repetição (Deleuze), além de questões relacionadas à origem no sentido benjaminiano, para, depois, fazermos uma análise fílmica detalhada das sequências em que temos as incursões musicais.

\section{Estribilhos e origem}

\section{Em Mil Platôs, Deleuze e Guattari (1997)}

desenvolvem o conceito de "ritornelo" como figura da territorialização: é o cantarolar no escuro, aquilo que nos proporciona a sensação de estarmos em casa, ou o pássaro cujo canto marca 0 seu território geográfico. 0 termo vem do campo da Música e alguns exemplos dos filósofos também. Mais do que isso, o ritornelo é, para os autores, "0 conteúdo propriamente musical, 0 bloco de conteúdo próprio da música" (DELEUZE; GUATTARI, 1997, p.88). Ao mesmo tempo, consideram a música como a operação ativa que desterritorializa as forças territorializantes do ritornelo, levando-o a uma linha de fuga, a uma transversal criadora. Pois o ritornelo também supõe forças de desterritorialização e reterritorialização.

Embora 0 emprego por Deleuze e Guattari de palavras como "território" (e, consequentemente, também de "desterritorialização" e "reterritorialização") esteja para além de seu campo semântico geográfico original, não deixa de ser curioso que, em Imagem-tempo, Deleuze (1990) volte a utilizar o conceito de ritornelo, aproximando-o, aí, a elementos rítmicos e temporais, que nos remetem mais facilmente ao campo da música².

Na verdade, a responsável pela versão em português do livro, Stella Senra, opta por traduzir ritournelle por "estribilho". 0 estribilho é apreendido por Deleuze (1990) como oposto e complementar ao "galope". Semelhante ao fato de que a ária de ópera faz a ação parar e 0 recitativo promove seu avanço, o estribilho é entendido por Deleuze como "recaída dos passados que se conservam" (DELEUZE, 1990, p.115) e 0 galope, como um elemento rítmico que faz avançar.

No campo específico da Música, ritornelo pode significar tanto a volta ao início de uma seção quanto o retorno da mesma parte orquestral (muitas vezes, em outras tonalidades) após estribilho: uma análise da música preexistente no filme A noiva estava de preto (1968) de Truffaut, em setembro de 2015. 0 presente texto é uma versão modificada, corrigida e ampliada.

2 Observação feita por Marcelo Carvalho, em conversa pessoal, em setembro de 2015. 
as partes solistas, 0 que corresponde à formaritornelo, geralmente encontrada nos primeiros e terceiros movimentos de concertos barrocos. Esta acepção de ritornelo se aproxima também do sentido geral de outro conceito deleuziano: a repetição, que nunca é simplesmente o retorno do Mesmo, mas que contém sempre em si a diferença (DELEUZE, 1968). Também o ritornelo musical barroco, ainda quando não tem nenhuma variação, nunca será o mesmo, já que ocorre depois que outros materiais musicais foram apresentados.

Outro aspecto importante em $A$ noiva estava de preto é que a imagem do noivo desfalecendo é um acontecimento decisivo, que se imobiliza na mente da protagonista Julie tal qual uma fotografia. Como observa Jean Collet (1968), o filme é "sobretudo a história de uma mulher fiel, que amou uma vez, uma única vez na vida. E cada gesto dela é conduzido pela fidelidade a esse amor perdido, esse amor que não pôde se realizar. Ela é levada por uma fatalidade implacável" (COLLET, 1968, tradução nossa). ${ }^{3}$ Veremos aqui que esta cena originária é retomada no filme de diferentes maneiras e pontos de vista, um mesmo sempre outro - uma forma de repetição no sentido deleuziano.

Em relação a este acontecimento decisivo, marcado curiosamente por uma fotografia tirada em seu exato momento, pensamos também nos conceitos de Walter Benjamim. Para Benjamim (2008a), a fotografia é o congelamento de um acontecimento, como a imagem levada ao Juízo Final: "Cada momento vivido transforma-se numa citation à l'ordre du jour - e esse dia é justamente 0 do juízo final" (BENJAMIM, 2008a, p.223, grifos

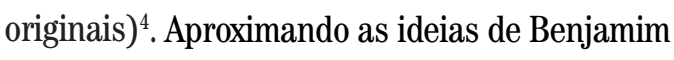
sobre a redenção à história da protagonista do filme, observamos que, para ser redimida, Julie Kohler deverá se apropriar totalmente do seu passado. Mais ainda, 0 acontecimento em si precisa ser redimido e, como explica Maurício Lissovsky (2005), a redenção dos acontecimentos só é possível porque eles estão orientados para 0 seu futuro, representado, no tempo diegético do filme de Truffaut, pela execução da vingança após o acontecimento originário.

Não por acaso o filme começa com uma máquina de xerox expelindo várias cópias da fotografia de Julie Kohler. Além de fazer menção à reprodutibilidade do cinema como obra de arte do século XX, tal como estudado por Benjamim (2008b) em texto bastante conhecido, é também uma referência ao congelamento da memória de Julie na cena originária sempre reproduzida no filme (a morte do noivo na saída da igreja) e a ação da personagem como o Anjo da Vingança

No original: "surtout I'histoire d'une femme fidèle, qui a aimé une fois, une seule fois dans sa vie. Et dont chaque geste est conduit par la fidélité à cet amour perdu, cet amour qui n’a pas pu se réaliser. Elle est entraînée par une fatalité implacable."

Também em seu texto Adrienne Mesurat, sobre o romance de Julien Green de mesmo título, Benjamim evoca a "presentificação" (Vergegenwärtigung) dos personagens "em seus instantes fatídicos" (in ihren schicksalhaften Momenten), que ocorre na narrativa do romance. Essa imagem nos remete à ideia do congelamento naquilo que estamos chamando de "acontecimento decisivo" no filme de Truffaut. 
sobre os cinco culpados, julgados por essa cena originária tal como no Juízo Final.

É preciso lembrar que, para Benjamim, a origem não está no início de algo, mas se manifesta em momentos de crise como uma imagem dialética, sempre originária (ou seja, algo que se encontra depois, e não antes) e redentora.

A origem, apesar de ser uma categoria totalmente histórica, não tem nada que ver com a gênese. 0 termo origem não designa 0 vir-a-ser daquilo que se origina, e sim algo que emerge do vir-a-ser e da extinção. A origem se localiza no fluxo do vir-a-ser como um torvelinho e arrasta em sua corrente 0 material produzido pela gênese. 0 originário não se encontra nunca no mundo dos fatos brutos e manifestos e seu ritmo só se revela a uma visão dupla, que o reconhece, por um lado, como restauração e reprodução, e por outro lado, e por isso mesmo, como incompleto e inacabado. [...]. A origem, portanto, não se destaca dos fatos, mas se relaciona com a sua pré e pós-história (BENJAMIM, 1984, p.67-68)

Assim, quando Julie vai ao encontro dos cinco homens, apresenta a cada um deles essa imagem pulsante da origem. A imagem dialética benjaminiana depende do trabalho da memória e contém, nela inscrito, 0 seu futuro, tal como as mulheres retratadas pelo pintor Fergus, todas elas imagens de Julie Kohler antes do encontro fatal entre os dois e cujo significado para o pintor só se desvela após o encontro.

Vamos, agora, analisar a utilização do Concerto para bandolim, de Vivaldi, e da Marcha Nupcial no filme de Truffaut.

\section{0 estribilho de Vivaldi e a enumeração}

0 Concerto para bandolim em Dó maior RV425, de Vivaldi, é ouvido quatro vezes no filme: no primeiro momento em que a protagonista Julie Kohler coloca o disco para tocar na vitrola, antes do primeiro assassinato (do personagem Bliss); após este ter sido cometido; durante o processo do segundo assassinato, após o personagem Coral ter ingerido a bebida envenenada; e, no começo do processo, para a execução do terceiro crime. Com exceção do segundo momento, em todas as outras ocorrências, ouvimos trechos do primeiro movimento do concerto (Tabela 1).

Tabela 1: Trechos do Concerto para bandolim, de Vivaldi, em A noiva estava de preto

\begin{tabular}{|l|l|l|l|}
\hline Trecho & \multicolumn{1}{|c|}{ Tempo } & \multicolumn{1}{|c|}{$\begin{array}{c}\text { Movimento do } \\
\text { concerto, compassos }\end{array}$} & \multicolumn{1}{c|}{ Sequência no filme } \\
\hline 1 & $12^{\prime} 13^{\prime \prime}-12^{\prime} 21^{\prime \prime}$ & Allegro (I), 1-4 & Julie coloca o disco do concerto para tocar na vitrola. \\
\hline 2 & $16^{\prime} 40^{\prime \prime}-17^{\prime} 24^{\prime \prime}$ & Adagio (II) completo & Após 0 assassinato de Bliss, imagens da écharpe de Julie voando. \\
\hline 3 & $31^{\prime} 55^{\prime \prime}-33^{\prime} 28^{\prime \prime}$ & Allegro (I), até 0 compasso 35 & Após Coral ter ingerido a bebida envenenada, Julie começa a dançar. \\
\hline 4 & $42^{\prime} 12^{\prime \prime}-42^{\prime} 23^{\prime \prime}$ & Allegro (I), compassos 5-8 & Julie, passando-se pela professora, escreve bilhete para filho de Morane. \\
\hline
\end{tabular}


Observamos, então, que a música acompanha o processo de enumeração pelo qual é construída a narrativa de Truffaut e que é, como ele mesmo observou, próprio dos contos de fada. Da mesma forma, os cinco homens, Bliss (Claude Rich), Coral (Michel Bouquet), Morane (Michel Lonsdale), Fergus (Charles Denner) e Delvaux (Daniel Boulanger), vão sendo, um a um, eliminados.

Em todos os contos, a narrativa se baseia na enumeração. Cachinhos de Ouro entra na casa dos três ursos. Vê as três tigelas. A sopa de Papai Urso está quente demais. A de Mamãe Ursa está fria demais. A do Bebê Urso está bem no ponto. Esse princípio de narração me agrada muito $^{5}$ (COLLET, 1968, tradução nossa).

Além disso, o Allegro do concerto barroco de Vivaldi, utilizado por Truffaut em quase todos os momentos, está na forma-ritornelo: sua primeira seção, em que 0 bandolim toca junto com os outros instrumentos da orquestra, está sempre retornando, seja em outras tonalidades, seja, tal como ocorre ao final do concerto, igual ao início. Portanto, a própria estrutura da música é calcada na repetição.

0 trecho 1 da tabela corresponde à primeira vez em que vemos a personagem Julie colocando o disco compacto com o Concerto para bandolim, de Vivaldi, na vitrola. Com efeito, esta imagem e 0 som dos primeiros compassos do concerto ficarão, depois disso, associados à personagem e ao seu plano de vingança.

Esses compassos são bem marcantes não só porque fazem parte do ritornelo do concerto, retornando igualmente no filme, mas também por causa de sua própria estrutura musical (Figura 1): notas agudas repetidas três vezes no bandolim, assim como nos primeiros violinos da orquestra que o dobram e nos segundos violinos; a figuração rítmica é a mesma nesses três grupos de instrumentos em todo 0 primeiro compasso e na metade do segundo; e, finalmente, a segunda frase musical (compassos 3-4) é a repetição da primeira (compassos 1-2).

Figura 1: Compassos 1 - 4 (partes do bandolim, violinos I e II) do Allegro do Concerto para bandolim em Dó Maior, de Vivaldi.

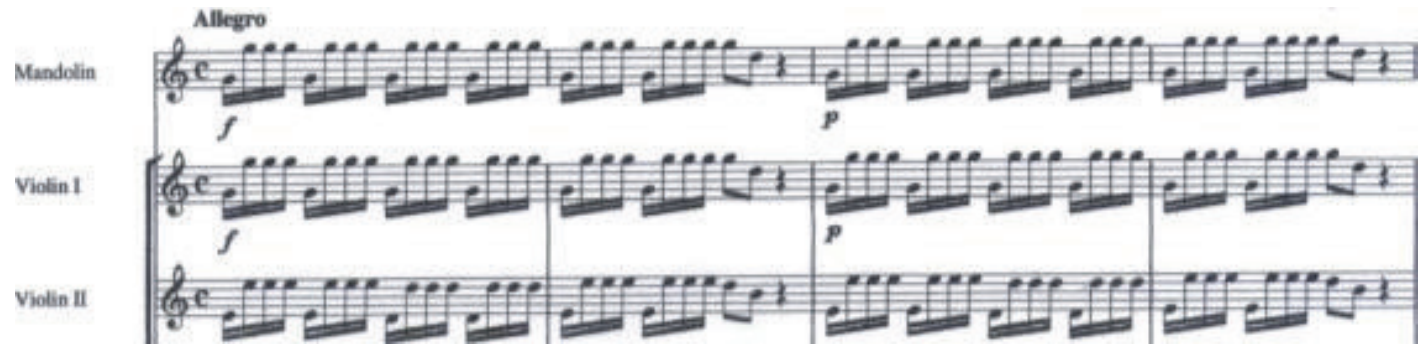

Fonte: Mainstream Music

No original da entrevista de Truffaut a Collet : "Dans tous les contes, le récit est basé sur l'énumération. Boucle d'or s'introduit dans la maison des trois ours. Elle voit les trois bols. La bouillie de Papa-Ours est trop chaude. Celle de Maman-Ours est trop froide. Celle de Bébé-Ours était tout juste bien. C'est un principe de narration qui me plaît beaucoup". 
Essa frase repetida termina no quinto grau da tonalidade principal Dó Maior, tendo um caráter suspensivo. Esse efeito de suspense pode ser sentido também no filme em relação à personagem Julie: será que ela vai dar prosseguimento ao seu plano de vingança? Conseguirá matar sua vítima? Será descoberta?

Quando Julie vai ao encontro de Coral, sua segunda vítima, já estamos certos de que o plano da mulher é matá-lo, embora as dúvidas sobre 0 seu sucesso ou não permaneçam. De qualquer modo, é como um recomeço e mais uma parte da enumeração deste conto de fadas.

Se, no trecho 1, víramos a imagem do disco, confirmando que a música é diegética, no trecho 3 , Julie faz menção à própria peça musical, chamando a atenção do espectador para ela: a personagem pergunta a Coral se ele gosta de bandolim e, após ingerir a bebida envenenada, 0 homem coloca o disco para tocar. A peça de Vivaldi continua a ser evocada pelos personagens, pois Coral diz, a seguir: "C'est très joli, je ne l'avais jamais entendu" ("É muito belo, nunca havia ouvido"); ao que Julie, anunciando que vai dançar para ele, responde: "Écoutez, c'est le mouvement rapide" ("Ouça, é o movimento rápido").

Essa evocação da música diegética pelos personagens faz com que ela seja 0 contrário das melodias inaudíveis, que Claudia Gorbman (1987) definira a respeito do cinema clássico narrativo. É a própria Gorbman (2007) que destaca esse modo de chamar a atenção para a música nos filmes, estando tal procedimento, em alguns diretores, associado com uma marca de autoria em relação ao elemento musical.

No trecho 3, durante a dança de Julie no apartamento de Coral, o Allegro, de Vivaldi, vai sendo mixado a uma valsa extradiegética, que passa a ser ouvida em seu lugar, embora continuemos a ver a imagem do disco na vitrola. A música original de Herrmann já havia substituído o som da música de Vivaldi na sequência anterior, quando Julie prepara a infusão que matará Coral, enquanto vemos a imagem do disco na vitrola, evocando-nos a imagem que víramos durante 0 trecho 1. Não é mais preciso ouvir a peça de Vivaldi: já sabemos que ela e o disco de onde provém são os símbolos do plano de vingança de Julie.

Essa substituição do concerto de Vivaldi pela música de Bernard Herrmann nos mostra 0 inverso do que aconteceu durante a montagem da sequência do assassinato do primeiro homem, Bliss. Como vemos na tabela, ouvimos o Adagio, 0 movimento lento do concerto de Vivaldi, enquanto a écharpe branca de Julie voa pela paisagem de praia e montanha do sul da França (trecho 2). É um momento poético, em que o espectador tem tempo para contemplar a paisagem, e isso depois do instante brutal em que Julie empurrara Bliss da janela. 0 lenço planando lentamente na horizontal é um contraste em relação à queda vertical brusca do homem. Jean Collet (1977) observa que a morte de Bliss passa a ter, na tela, menos importância 
do que 0 voo do lenço ao som de Vivaldi, que "nos leva a um espaço vertiginoso [...], transformando a morte em volúpia [...], a queda em elã" (COLLET, 1977, p.128, tradução nossa) ${ }^{6}$, desviando o sentido trágico da morte para uma apreciação estética da paisagem e da música.

Na verdade, esse trecho 2 com o concerto de Vivaldi no filme foi um ponto de discórdia entre o compositor Bernard Herrmann e François Truffaut, pois o diretor substituiu a música original de Herrmann com a indicação Lento ${ }^{7}$ pelo Adagio, de Vivaldi, também uma peça de andamento lento. Truffaut chegou a afirmar depois que considerava a música de Herrmann escrita para seu filme anterior, Fahrenheit 451, muito superior à de A noiva estava de preto. Talvez isso explique a substituição nessa sequência. $\mathrm{Ou}$, talvez, Truffaut tenha preferido relacionar, mais uma vez, o concerto de Vivaldi à execução do plano de Julie. Mesmo que este seja o movimento lento, ouvimos o timbre do bandolim e 0 espectador pode reconhecer 0 trecho como relacionado ao Allegro do trecho 1.

De fato, a escolha de um concerto para esse instrumento em especial (tão incomum na música de concerto, mas que, por outro lado, foi utilizado com certa frequência no período barroco) também deve ser destacada, o que já, por si só, confere uma impressão de estranheza ao filme.

\section{0 estribilho da Marcha Nupcial e a cena originária}

A Marcha Nupcial, de Mendelssohn, é parte de Sonhos de uma noite de verão, música incidental que 0 compositor fez para a peça homônima de William Shakespeare e que, depois, transformou em uma suíte orquestral.

No filme de Truffaut, ouvimos o seu tema nos créditos iniciais, em meio à música original de Bernard Herrmann, e ele tem uma função quase que referencial de "casamento". Da mesma forma como a Marseillaise era praticamente um clichê de "revolução" em filmes do cinema silencioso, acompanhando sequências de levantes populares e insurgências para além de uma "francidade" podemos ouvi-la, em momentos assim, na trilha original de Edmund Meisel para $O$ encouraçado Potiemkim (Sergei Eisenstein, 1925) e na de Gottfried Huppertz para Metrópolis (Fritz Lang, 1927) -, a Marcha Nupcial, de Mendelssohn, foi, já naquela época, associada a cenas de casamento. Nesses casos, partindo do conceito de mito de Roland Barthes (1975), a Marseillaise e Marcha Nupcial, com seus significantes e significados, tornam-se novos significantes de um sistema semiológico segundo: mitos da revolução e do casamento.

Ainda sobre essa sequência, vamos considerar a análise de Justin London (2000) sobre as convenções 
para a música dos créditos iniciais de filmes. London identifica um esquema $\mathrm{ABA}$ em grande parte desses créditos: 0 tema de abertura (A) está associado ao título do filme e pode se referir a um personagem específico ou a um local, ou, ainda, evocar o gênero do filme. Por sua vez, o tema (B), de orquestração tipicamente reduzida e mais lírico, seria normalmente associado à protagonista feminina. No caso de A noiva estava de preto, o tema B é a própria Marcha Nupcial, associada à protagonista Julie, e os créditos terminam com a sua audição. Já o tema A, ouvido antes de B (no filme de Truffaut, não temos a repetição de A depois dele), é uma variação de Bernard Herrmann a partir do próprio motivo da Marcha Nupcial, procedimento que será bastante empregado no filme, em especial, em uma das sequências que analisaremos.

A imagem que sai repetidamente na máquina de xerox dos créditos iniciais (Figura 2) é a foto do quadro pintado por Fergus, o quarto homem assassinado, com a própria Julie como modelo e que é fotografado como indício do crime. Fergus é o único homem que não tem seu assassinato ao som do concerto de Vivaldi ou da Marcha Nupcial. Porém, esta última, ao ser ouvida sobre a foto do quadro no início do filme, leva à associação, como num flashforward $d^{8}$, à morte do personagem. Além disso, o fato de estar nos créditos iniciais confirma o caráter especial de Fergus. Ele é, efetivamente, o único que provoca uma hesitação de Julie, um lampejo de paixão que quase a lança para fora da completude de seu plano de vingança.

\section{Figura 2: Foto do quadro que tem Julie Kohler} como modelo; créditos iniciais.

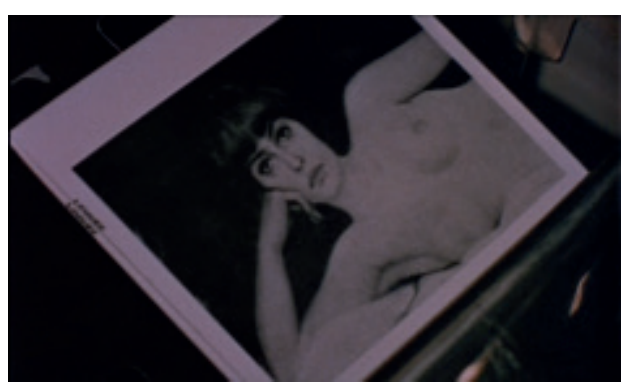

Fonte: The bride wore black (DVD)

Diferentemente do concerto de Vivaldi, a Marcha Nupcial não tem tão marcadamente 0 significado de enumeração, embora ponha sempre em destaque os momentos da consumação dos assassinatos. Na primeira vez em que ouvimos a sua citação orquestral na música de Herrmann depois dos créditos, Julie revela a Bliss o seu nome ("Eu sou Julie Kohler") e o empurra para a morte. No processo de assassinato de sua próxima vítima (Coral), ouvimos o extrato preexistente de Mendelssohn, enquanto Julie conta ao moribundo Coral quem é e por que está ali. A Marcha Nupcial adquire, nesses momentos, o significado de revelação, não só para Bliss e Coral como também para 0 espectador. 
Durante 0 relato de Julie a Coral (trecho 3 da Tabela 2), vemos uma sequência de planos de flashback: 0 relógio da torre da igreja em plano próximo, o tilt para baixo ao longo da torre da igreja até chegar ao seu pórtico no momento em que se dá a saída dos noivos e dos convidados, um afastamento da câmera para trás e 0 posicionamento de todos para uma fotografia e a queda do noivo após receber o tiro (Figura 3).

\section{A partir daí, a Marcha Nupcial remete} continuamente a esta cena originária: não vemos mais o plano da fotografia sendo feita no momento da morte, mas é como se Julie evocasse esse momento com a estaticidade da fotografia. Por outro lado, o ponto de vista com que a sequência de planos foi mostrada, assim como as variações seguintes, de outros pontos de vista, durante as novas revelações de Julie, estão em terceira pessoa, ou seja, não fazem parte de uma câmera subjetiva. A música, mais do que as imagens mostradas no filme, é, para Julie, um estribilho que faz voltar sempre a mesma lembrança.

Assim, a Marcha Nupcial é ouvida 11 vezes no filme, seja como extrato de gravação da música preexistente de Mendelssohn, seja como citação orquestral dentro música original de Bernard Herrmann (Tabela 2).

Das 11 incursões musicais, observamos que sete estão durante a conversa entre Julie e Morane (este, aprisionado em um armário, segundo o plano de Julie, o que leva, efetivamente, à sua morte). É o principal momento de revelação no
Figura 3: Primeira apresentação dos planos da "cena originária"
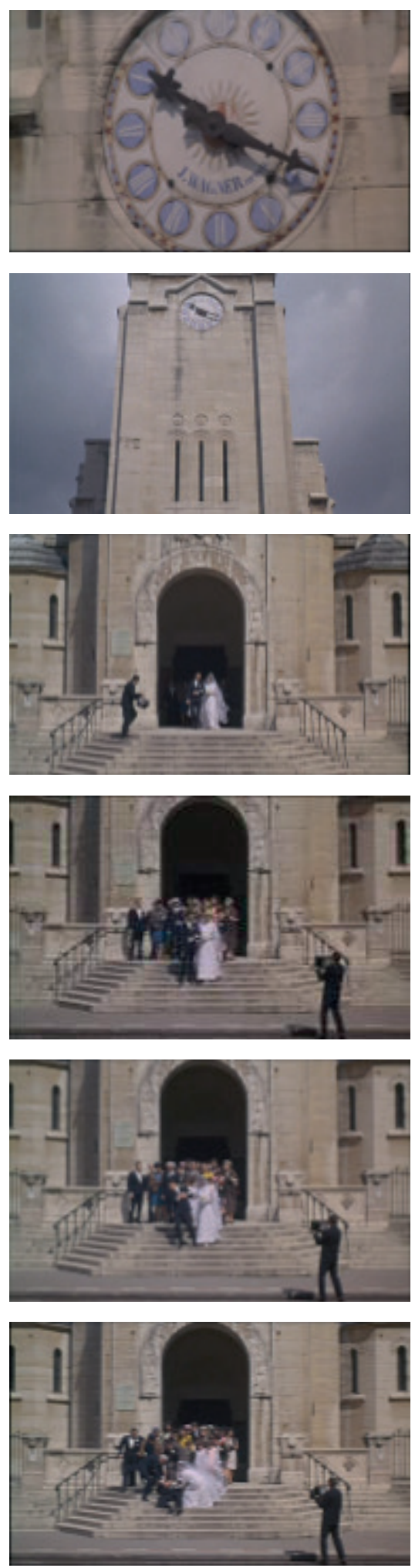

Fonte: The bride wore black (DVD)

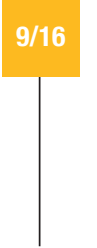

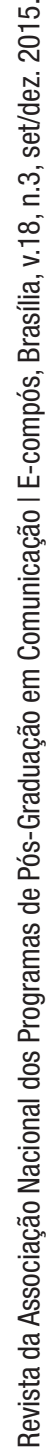


Tabela 2: Trechos da Marcha Nupcial, de Mendelssohn, em A noiva estava de preto

\begin{tabular}{|l|l|l|l|}
\hline Trecho & \multicolumn{1}{|c|}{ Tempo } & $\begin{array}{c}\text { Música preexistente de } \\
\text { Mendelssohn ou citação } \\
\text { orquestral de Herrmann }\end{array}$ & \multicolumn{1}{|c|}{ Momento do filme } \\
\hline 1 & $0^{\prime} 55^{\prime \prime}-1^{\prime} 29^{\prime \prime}$ & $\begin{array}{l}\text { Mendelssohn } \\
\text { (antes, citação) }\end{array}$ & Créditos iniciais \\
\hline 2 & $16^{\prime} 07^{\prime \prime}-16^{\prime} 18^{\prime \prime}$ & citação & Julie revela seu nome a Bliss e o empurra da janela. \\
\hline 3 & $35^{\prime} 03^{\prime \prime}-35^{\prime} 42^{\prime \prime}$ & Mendelssohn & $\begin{array}{l}\text { Julie revela a Coral que já se encontraram, mas que ela } \\
\text { estava de branco. }\end{array}$ \\
\hline 4 & $54^{\prime} 07^{\prime \prime}-54^{\prime} 52^{\prime \prime}$ & Mendelssohn & Julie começa a explicar a Morane quem ela é. \\
\hline 5 & $55^{\prime} 19^{\prime \prime}-55^{\prime} 25^{\prime \prime}$ & citação & Mesma sequência anterior - Coral à janela. \\
\hline 6 & $55^{\prime} 39^{\prime \prime}-55^{\prime} 45^{\prime \prime}$ & citação & Mesma sequência anterior - Morane junto com Coral apontando a arma. \\
\hline 7 & $55^{\prime} 46^{\prime \prime}-55^{\prime} 56^{\prime \prime}$ & citação & Mesma sequência anterior - Coral busca balas para a colocar na arma. \\
\hline 8 & $56^{\prime} 16^{\prime \prime}-56^{\prime} 28^{\prime \prime}$ & citação & Mesma sequência anterior - Delvaux olha para a arma sobre a mesa. \\
\hline 9 & $56^{\prime} 57^{\prime \prime}-57^{\prime} 08^{\prime \prime}$ & citação & Mesma sequência anterior - o noivo caindo (ponto de vista da janela). \\
\hline 10 & $58^{\prime} 16^{\prime \prime}-58^{\prime} 25^{\prime \prime}$ & Mendelssohn & $\begin{array}{l}\text { Após Julie dizer para Morane: "Para o senhor é uma história antiga, } \\
\text { mas para mim ela recomeça todas as noites". }\end{array}$ \\
\hline 11 & $107^{\prime} 01^{\prime \prime}-107^{\prime} 36^{\prime \prime}$ & Mendelssohn & No momento do assassinato de Delvaux. \\
\hline
\end{tabular}

filme, em que 0 espectador vê novamente a cena originária de outro ponto de vista: 0 dos cinco homens que manuseavam o rifle no andar alto do prédio em frente à igreja.

As imagens do trecho 4 se iniciam como uma variação das já mostradas no trecho anterior, de outro ponto de vista: o plano começa na glorieta da igreja, um tilt para baixo mostra toda a extensão da torre e vemos o relógio de longe. No entanto, no plano de plongée do pórtico da igreja, observamos que ele está vazio: é um momento anterior ao do tiro. Percebemos que vamos ser apresentados à versão de Morane dos fatos, embora este não diga em suas palavras a Julie 0 que exatamente aconteceu (ele segue repetindo: "foi um terrível acidente"). A imagem termina em um plano de grua que vai na direção da janela do apartamento onde estavam os cinco homens.

\section{A partir daí, as incursões da Marcha Nupcial} serão reorquestrações de Bernard Herrmann,

Usar um tema preexistente marcante do próprio filme e reorquestrá-lo é um procedimento comum e ocorreu também com a canção As time goes by, presente em diversos momentos na música orquestral de Max Steiner em Casablanca (Michael Curtiz, 1942), como analisado no artigo de Martin Marks (2000), Music, Drama, Warner Brothers: the cases of Casablanca and The Maltese Falcon.

10 Na música para cinema, o modo menor é costumeiramente associado a momentos tristes. 
imiscuídas em sua própria música orquestral original para 0 filme ${ }^{9}$, som de todas essas imagens do passado. Nesses trechos, o sentido associado à música não é mais o da progressão do plano de vingança de Julie nem o de revelação dos fatos, mas sim, de música de suspense, como se estivesse em um filme de Hitckcock, com quem Herrmann tanto trabalhou e que é homenageado por Truffaut com esse filme: quem foi 0 responsável pelo tiro?

Assim, no trecho 5, vemos Coral à janela, mas a arma não está com ele. No trecho 6, Morane está junto a Coral à janela e aponta a arma para fora, mas ela está sem balas. No trecho 7, Coral busca as balas para carregar a arma. No trecho 8, Delvaux olha para o rifle, deixado em cima da mesa do apartamento. Vemos, nessa própria descrição das cenas, uma progressão na tensão que se reflete também na música: os trechos 5 e 6 são iguais; no trecho 7, a música está no modo menor, fazendo um contraste e apontando para 0 triste desfech $0^{10}$; finalmente, no trecho 8,0 motivo inicial da Marcha é retomado quatro vezes na música de Herrmann por diferentes instrumentos, cada vez mais graves, em um crescendo de tensão e indicando que algo realmente irá acontecer.

0 caráter diferente deste trecho aponta para a resolução do mistério: a seguir, vemos Delvaux apontando a arma, Morane e Coral correndo para ele e 0 contendo em vão, sendo o trecho 90 do plano em plongée do noivo caindo. Nele, o motivo inicial da Marcha também é repetido, agora três vezes e com a orquestra completa. É interessante também observar que, tanto durante 0 trecho 6 quanto pouco antes do 7, as imagens são variações daquelas vistas nos trechos 3 e 4 .

A última incursão musical da Marcha Nupcial da sequência (trecho 10) é oriunda da música preexistente de Mendelssohn, como a que dá início a ela (trecho 4), e volta a se relacionar com Julie. A fala da personagem, que desencadeia a música, é como uma conclusão de toda a estrutura de estribilho e variações da sequência e do filme inteiro: "Para o senhor é uma história antiga, mas, para mim, ela recomeça todas as noites". Ou seja, para Julie, é um eterno recomeço, um estribilho que retorna, assim como a imagem de seu noivo sendo morto ou o modo de funcionamento das duas músicas preexistentes do filme (o concerto de Vivaldi e a Marcha Nupcial, de Mendelssohn).

Vemos, durante o trecho 10, o plano da saída dos noivos, que agora é frontal. Mesmo não sendo um plano subjetivo de Julie, está mais aproximado à perspectiva dela do que os planos em plongée apresentados durante a sequência. Seria, considerando as ideias de Deleuze (1990), um plano meio objetivo, meio subjetivo, tal como o filósofo observa ser comum na Nouvelle Vague. Ainda neste trecho, as imagens do dia do casamento se alternam com as da infância de Julie junto ao noivo David.

Na continuação das imagens da infância de Julie, agora ao som da música de Herrmann, 
percebemos uma vitrola com um disco, o que nos leva a perguntar: seria o da Marcha Nupcial, em uma obsessão com o casamento, justificada pelas últimas imagens da sequência, em que vemos Julie criança vestida de noiva, de braço dado com David? Ou seria o concerto para bandolim de Vivaldi, justificando a presença desta música relacionada com os dois primeiros crimes? É preciso notar que a Marcha Nupcial é música extradiegética, embora tenhamos a tendência de associá-la ao pensamento de Julie, enquanto o concerto de Vivaldi faz parte da diegese e tem como fonte sonora um disco da personagem.

De todo modo, logo a seguir, ao som de sinos e da música de Herrmann, volta a imagem da saída dos noivos da igreja em plano frontal, mais próximo ainda do que o do trecho anterior, em um meio plano médio de Julie e David. Esse novo retorno destaca tal momento como a cena originária do filme, que assola Julie.

Ao longo da vingança da protagonista, a sequência de mortes, tratada de maneira mecânica no filme, acaba tornando o luto de Julie risível. Além disso, a personagem é incapaz de sentir qualquer resquício de compaixão pelos destinatários de sua urdida vingança - mesmo por Fergus, que quase lhe faz desistir de ir até 0 fim. Essa forma ritualística da execução da vingança de Julie retira a qualidade trágica de sua história. "Em todo luto existe uma tendência à mudez" (BENJAMIM, 1984, p.247): o luto permanente de Julie pelo noivo faz com que se perca a conexão com esse objeto de luto. A noiva de preto se torna algo alegórico, tal como a constante repetição da Marcha Nupcial.

A ação de Julie de colocar 0 disco com 0 concerto de Vivaldi ou a possível associação da Marcha Nupcial ao pensamento da protagonista podem também ser relacionadas com 0 conceito psicanalítico de recalque de Freud ${ }^{11}$, visto pela ótica de Deleuze (1968): a personagem repete a música e prossegue seu plano de vingança porque ela não conseguiu elaborar a lembrança da morte de seu noivo e, portanto, o recalque "faz da própria repetição uma verdadeira 'coerção', uma “compulsão"” (DELEUZE, 1968, p.26).

Julie tem consciência de que seu único desejo é trazer David de volta, assim como de que isso é impossível. Diante dessa impossibilidade, repete aquilo que é possível: a música e a memória da cena originária. David é um morto que foi embora muito cedo e rápido, sem que Julie tenha consigo lhe prestar devidamente as exéquias, por mais que esteja presente 0 tempo todo em sua memória.

0 último trecho da Marcha Nupcial (de número 11) coincide com o final do filme: Julie, finalmente, consegue matar o último dos homens responsáveis pela morte de seu noivo e, para isso, tomou uma 
atitude extrema: entregou-se e confessou seus crimes para ficar na mesma prisão em que Delvaux estava confinado e ter a oportunidade de matá-lo. Neste trecho, ouvimos a Marcha por mais tempo: vemos a palavra "Fim" e a tela escurecer. É um verdadeiro fechamento, pois nada mais importa a Julie: sua vingança foi cumprida e não há nada mais que ela busque na vida.

\section{Considerações finais}

No filme $A$ noiva estava de preto, tanto o Concerto para bandolim em Dó Maior RV425, de Vivaldi, quanto a Marcha Nupcial, de Mendelssohn, são peças musicais preexistentes que retornam continuamente ao longo do filme e se relacionam à vingança da personagem Julie.

Essas repetições contêm em si a diferença, como no conceito deleuziano de ritornelo, traduzido em Imagem-tempo como estribilho: seja a partir da observação de características formais simples, como diferenças no número de compassos utilizados, imagens diversas associadas aos trechos musicais ou pelo uso de arranjos (no caso da Marcha Nupcial, as reorquestrações do tema contidas na própria trilha original de Bernard Herrmann), seja no sentido da repetição que nunca se refere ao Mesmo, por mais que contenha material idêntico.

No caso do Concerto para bandolim, de Vivaldi, as suas incursões musicais se relacionam ao processo da enumeração, bastante presente em contos de fada e de que 0 filme de Truffaut se utiliza. Já a Marcha Nupcial, de Mendelssohn, com relação referencial e mítica com 0 tema do casamento, é associada à revelação de Julie aos personagens Bliss, Coral e Morane (assim como ao espectador) e às reconstituições da cena originária da morte do noivo: quase todas as incursões musicais desta peça estão na sequência em que Julie, após trancar Morane no armário, conversa com ele, e vemos essas evocações imagéticas do acontecimento a partir de diversos pontos de vista, com variações nos planos, enquanto ouvimos diversas vezes, repetido e diferente, o motivo da Marcha Nupcial.

Semelhante à maneira como Benjamim compreende a origem, tal acontecimento decisivo é evocado no tempo diegético do filme, apontando também para o futuro desde a primeira imagem: a foto do quadro do pintor Fergus com a imagem de Julie nos créditos. Na verdade, Fergus já pintava várias mulheres com os traços de Julie, como que esperando pela chegada futura do Anjo da Vingança. A prova do crime, confeccionada pela própria vítima, levará à prisão de Julie e à possibilidade de que esta possa dar prosseguimento à vingança no cárcere. Na tela preta da última incursão da Marcha Nupcial, passado, presente e futuro se congelam.

\section{Referências}

A NOIVA estava de preto (The Bride wore Black). Direção: François Truffaut. França/Itália, 1968. Título original: La mariée était en noir. 1 DVD (108 min), cor. Produzido por World Films. 
BARTHES, Roland. Mitologias. São Paulo: Difel, 1975.

BENJAMIM, Walter. Origem do drama barroco alemão. São Paulo: Brasiliense, 1984.

. Sobre o conceito da História. In:

. Magia e técnica, arte e política. São Paulo:

Brasiliense, 2008a.

. A obra de arte na época da reprodutibilidade.

In:___ Magia e técnica, arte e política. São

Paulo: Brasiliense, 2008b.

. Adrienne Mesurat. Disponível em: < http://

www.textlog.de/benjamin-kritik-adrienne-mesurat-

julien-green.html > . Acesso em : 26 set. 2015.

COLLET, Jean. La mariée était en noir: Un policier?

Un conte de fées? Une histoire d'amour? Tout cela

et quelque chose d'autre... Mais lisez l'interview de

François Truffaut. Télérama, n.954, 28 avril 1968.

. Le cinéma de François Truffaut. Paris : P.

Lherminier, 1977.

DELEUZE, Gilles. Différence et répétition. Paris:

Presses Universitaires de France, 1968.

. A imagem-tempo. Tradução: Stella Senra.

São Paulo: Brasiliense, 1990.

DELEUZE, Gilles; GUATTARI, Felix. Mil Platôs. São

Paulo: Editora 34, 1997. v. 4.

FREUD, Sigmund. Recalque. In: Os Filósofos Através

dos Textos. São Paulo: Paulus, 1997.

GORBMAN, Claudia. Unheard Melodies: Narrative

Film Music. London: BFI Publishing, 1987.

. Auteur music. In: GOLDMARK, Daniel;

KRAMER, Lawrence; LEPPERT, Richard (Org.).

Beyond the soundtrack: representing music in cinema. Los Angeles: University of California Press, 2007.

LISSOVSKY, Maurício. A memória e as condições poéticas do acontecimento. In: GONDAR, Jô; DODEBEI,
Vera. 0 que é Memória Social? Rio de Janeiro:

Contracapa, 2005.

LONDON, Justin. Leitmotifs and Musical Reference in the Classical Film Score. In: BUHLER, James; FLINN, Caryl; NEUMEYER, David (Org.). Music and Cinema. Hanover: Wesleyan University Press, 2000.

MARKS, Martin. Music, Drama, Warner Brothers: the cases of Casablanca and The Maltese Falcon. In: BUHLER, James; FLINN, Caryl; NEUMEYER, David (Org.). Music and Cinema. Hanover: Wesleyan University Press, 2000.

WROBEL, Bill. Bernard Herrmann's The bride wore black. Disponível em: < http://www.filmscorerundowns. net/herrmann/index.html> . Acesso em: 21 set. 2014. 


\section{The bride and the refrain: an analysis of preexisting music in a film by Truffaut}

\section{Abstract}

In The bride wore black (François Truffaut, 1968), the main character Julie revenges herself on the five men responsible for the death of her groom. Two preexisting pieces, the Mandolin concert by Vivaldi and Mendelssohn`s Wedding March, accompany her like refrains. The first one is related to the enumeration mode of the narrative, like in fairy tales and characterized by repetition, which is also present in the music structure. As for the Wedding March, it is heard as the original scene, the couple's exit from the church, is repeated with differences. We consider the concepts of refrain, repetition (Deleuze) and origin (Benjamim) and we proceed to a film analysis of the sequences with the two preexisting pieces.

\section{Keywords}

Cinema. Music in cinema. François Truffaut.

Film analysis.

\section{La novia y el ritomelo: análisis de la música preexistente en una película de Truffaut}

\section{Resumen}

En La novia vestía de negro (François Truffaut, 1968), la protagonista Julie se venga de los cinco hombres responsables por la muerte de su novio. Dos músicas preexistentes, el Concierto para mandolina de Vivaldi y la Marcha Nupcial de Mendelssohn, la acompañan como ritornelos. La primera se relaciona al modo de enumeración de la historia, cómo en los cuentos de hada y marcado por la repetición, que está también en la estructura de la música. Por su vez, la Marcha Nupcial es oída a medida que la escena originaria, la salida de la copia de la iglesia, es repetida con diferencias. Consideramos los conceptos de ritornelo, repetición (Deleuze) y origen (Benjamim) y hacemos un análisis de las secuencias con las dos músicas preexistentes.

\section{Palabras clave}

Cine. Música en el cine. François Truffaut. Análisis fílmico. 


\section{Expediente}

A revista E-Compós é a publicação científica em formato eletrônico da Associação Nacional dos Programas de Pós-Graduação em Comunicação (Compós). Lançada em 2004, tem como principal finalidade difundir a produção acadêmica de pesquisadores da área de Comunicação, inseridos em instituições do Brasil e do exterior.

\section{E-COMPÓS I www.e-compos.org.br I E-ISSN 1808-2599}

Revista da Associação Nacional dos Programas de Pós-Graduação em Comunicação.

Brasília, v.18, n.3, set./dez. 2015.

A identificação das edições, a partir de 2008, passa a ser volume anual com três números.

Indexada por Latindex I www.latindex.unam.mx

\section{CONSELHO EDITORIAL}

Alexandre Farbiarz, Universidade Federal Fluminense, Brasil Alexandre Rocha da Silva, Universidade Federal do Rio Grande do Sul, Brasil Ana Carolina Damboriarena Escosteguy, Pontifícia Universidade Católica do Rio Grande do Sul, Brasil

Ana Carolina Rocha Pessôa Temer, Universidade Federal de Goiás, Brasil Ana Regina Barros Rego Leal, Universidade Federal do Piauí, Brasil Andrea França, Pontifícia Universidade Católica do Rio de Janeiro, Brasil André Luiz Martins Lemos, Universidade Federal da Bahia, Brasil Antonio Carlos Hohlfeldt, Pontifícia Universidade Católica do Rio Grande do Sul, Brasil

Arthur Ituassu, Pontifícia Universidade Católica do Rio de Janeiro, Brasil Álvaro Larangeira, Universidade Tuiuti do Paraná, Brasil Ângela Freire Prysthon, Universidade Federal de Pernambuco, Brasil César Geraldo Guimarães, Universidade Federal de Minas Gerais, Brasil Cláudio Novaes Pinto Coelho, Faculdade Cásper Líbero, Brasil Daisi Irmgard Vogel, Universidade Federal de Santa Catarina, Brasil Denize Correa Araujo, Universidade Tuiuti do Paraná, Brasil Eduardo Antonio de Jesus, Pontifícia Universidade Católica de Minas Gerais, Brasil

Daniela Zanetti, Universidade Federal do Espirito Santo, Brasil Eduardo Vicente, Universidade de São Paulo, Brasil Elizabeth Moraes Gonçalves, Universidade Metodista de São Paulo, Brasil Erick Felinto de Oliveira, Universidade do Estado do Rio de Janeiro, Brasil Francisco Elinaldo Teixeira, Universidade Estadual de Campinas, Brasil Francisco Paulo Jamil Almeida Marques, Universidade Federal do Paraná, Brasil

Gabriela Reinaldo, Universidade Federal do Ceará, Brasil Goiamérico Felício Carneiro Santos, Universidade Federal de Goiás, Brasil Gustavo Daudt Fischer, Universidade do Vale do Rio dos Sinos, Brasil Herom Vargas, Universidade Municipal de São Caetano do Sul, Brasil Itania Maria Mota Gomes, Universidade Federal da Bahia, Brasil
Janice Caiafa, Universidade Federal do Rio de Janeiro, Brasil Jiani Adriana Bonin, Universidade do Vale do Rio dos Sinos, Brasil José Afonso da Silva Junior, Universidade Federal de Pernambuco, Brasil José Luiz Aidar Prado, Pontifícia Universidade Católica de São Paulo, Brasil Juçara Gorski Brittes, Universidade Federal de Ouro Preto, Brasil Kati Caetano, Universidade Tuiuti do Paraná, Brasil

Lilian Cristina Monteiro França, Universidade Federal de Sergipe, Brasil Liziane Soares Guazina, Universidade de Brasília, Brasil Luíza Mônica Assis da Silva, Universidade de Caxias do Sul, Brasil Luciana Miranda Costa, Universidade Federal do Pará, Brasil Malena Segura Contrera, Universidade Paulista, Brasil Maria Ogécia Drigo, Universidade de Sorocaba, Brasil Maria Ataide Malcher, Universidade Federal do Pará, Brasil Marcia Tondato, Escola Superior de Propaganda e Marketing, Brasil Marcel Vieira Barreto Silva, Universidade Federal da Paraíba, Brasil Maria Clotilde Perez Rodrigues, Universidade de São Paulo, Brasil Maria das Graças Pinto Coelho, Universidade Federal do Rio Grande do Norte, Brasil

Mauricio Ribeiro da Silva, Universidade Paulista, Brasil

Mauro de Souza Ventura, Universidade Estadual Paulista, Brasil Márcio Souza Gonçalves, Universidade do Estado do Rio de Janeiro, Brasil Micael Maiolino Herschmann, Universidade Federal do Rio de Janeiro, Brasil Mirna Feitoza Pereira, Universidade Federal do Amazonas, Brasil Nísia Martins Rosario, Universidade Federal do Rio Grande do Sul, Brasil Potiguara Mendes Silveira Jr, Universidade Federal de Juiz de Fora, Brasil Regiane Regina Ribeiro, Universidade Federal do Paraná, Brasil Rogério Ferraraz, Universidade Anhembi Morumbi, Brasil Rose Melo Rocha, Escola Superior de Propaganda e Marketing, Brasil Rozinaldo Antonio Miani, Universidade Estadual de Londrina, Brasil Sérgio Luiz Gadini, Universidade Estadual de Ponta Grossa, Brasil Simone Maria Andrade Pereira de Sá, Universidade Federal Fluminense, Brasil Veneza Mayora Ronsini, Universidade Federal de Santa Maria, Brasil Walmir Albuquerque Barbosa, Universidade Federal do Amazonas, Brasil

\section{COMISSÃO EDITORIAL}

Cristiane Freitas Gutfreind

Pontifícia Universidade Católica do Rio Grande do Sul, Brasil

Irene Machado

Universidade de São Paulo, Brasil

\section{CONSULTORES AD HOC}

Claudia Peixoto de Moura, Pontificia Universidade Católica do Rio Grande do Sul, Brasil Francisco Rüdiger, Pontifícia Universidade Católica do Rio Grande do Sul, Brasil Juremir Machado da Silva, Pontifícia Universidade Católica do Rio Grande do Sul, Brasil Maria Aparecida Baccega, Universidade de São Paulo, Brasil

Roberto Tietzmann, Pontifícia Universidade Católica do Rio Grande do Sul, Brasil

\section{EQUIPE TÉCNICA}

ASSISTENTE EDITORIAL I Márcio Zanetti Negrini

REVISÃO DE TEXTOS I Press Revisão

EDITORAÇÃO ELETRÔNICA I Roka Estúdio

CONTATO I revistaecompos@gmail.com
COMPÓS I www.compos.org.br

Associação Nacional dos Programas de Pós-Graduação em Comunicação

Presidente

Edson Fernando Dalmonte

Programa de Pós-Graduação em Comunicação

e Cultura Contemporânea - UFBA

edsondalmonte@uol.com.br

Vice-presidente

Cristiane Freitas Gutfreind

Programa de Pós-Graduação em Comunicação Social - PUC-RS cristianefreitas@pucrs.br

Secretário-Geral

Rogério Ferraraz

Programa de Pós-Graduação em Comunicação

Universidade Anhembi Morumbi

rogerioferraraz@anhembimorumbi.edu.br 